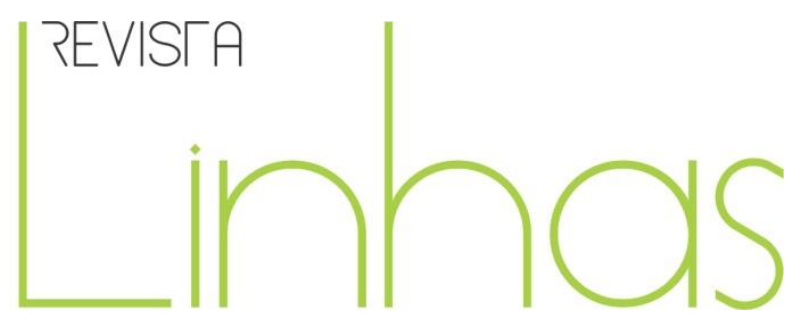

\title{
Análise da estrutura curricular do Curso de Licenciatura em Química ofertado no IFMT na modalidade EaD ${ }^{1}$
}

\begin{abstract}
Resumo
A estrutura curricular de um curso de licenciatura influencia diretamente no tipo de professor que por ela será formado. Assim, o objetivo deste estudo foi analisar a estrutura curricular do Curso de Licenciatura em Química, ofertado na modalidade EaD pelo IFMT Campus Cuiabá-Bela Vista, para verificar conformidades com os documentos oficiais nacionais e indicar ajustes necessários para sua adequação. Trata-se de uma análise documental, com abordagem qualitativa, ocorrida nos anos de 2016 e 2017. Verificou-se que a atual matriz, proposta no ano de 2012, atende a carga horária para o estágio supervisionado, para as atividades complementares e para a prática como componente curricular, porém não atende às 3.200 horas exigidas para um curso de licenciatura. Constatou-se que essa matriz contempla importantes e obrigatórias temáticas, tais como Libras, educação inclusiva, educação de jovens e adultos e educação ambiental, porém não aborda as questões da diversidade étnico-racial, por exemplo. Outro aspecto verificado é a ausência de discussões sobre história, epistemologia e/ou filosofia da ciência, educação CTS e tecnologias educacionais. Portanto, a estrutura curricular analisada atende em partes as diretrizes curriculares nacionais, necessitando de uma adequação quanto à carga horária total do curso que pode ser realizada pela inserção de disciplinas tanto de natureza específica quanto pedagógica.
\end{abstract}

Palavras-chave: Currículo. Diretrizes Curriculares. Formação de Professores. Legislação.

\section{Marcelo Franco Leão}

Universidade Federal do Rio

Grande do Sul - UFRGS - Porto

Alegre/RS - Brasil

marcelo.leao@cfs.ifmt.edu.br

José Claudio Del Pino

Universidade Federal do Rio

Grande do Sul - UFRGS - Porto

Alegre/RS - Brasil

delpinojc@yahoo.com.br

Eniz Conceição Oliveira

Universidade do Vale do Taquari - Univates - Lajeado/RS - Brasil eniz@univates.br

\section{Para citar este artigo:}

LEÃO, Marcelo Franco; DEL PINO, José Cláudio; OLIVEIRA, Eniz Conceição. Análise da estrutura curricular do Curso de Licenciatura em Química ofertado no IFMT na modalidade EaD. Revista Linhas. Florianópolis, v. 20, n. 42, p. 197-216, jan./abr. 2019. Título original: Analysis of the curricular framework for the Chemistry Licentiate Degree Course at the IFMT through DE.

DOI: $10.5965 / 1984723820422019197$

http://dx.doi.org/10.5965/1984723820422019197

\footnotetext{
${ }^{1}$ Este estudo contou com o subsídio financeiro do Edital 049/2017 da PROPES/IFMT e com o apoio da Coordenação de Aperfeiçoamento de Pessoal de Nível Superior (CAPES), relativo à bolsa de estudo para o doutoramento do primeiro autor.
} 


\title{
Analysis of the curricular framework for the Chemistry Licentiate degree Course at the IFMT through DE
}

\begin{abstract}
The curricular framework for a licentiate degree course has a direct influence on the type of teacher it will be training. Thus, the objective of this study is to analyze the curricular framework for the Chemistry Licentiate Degree Course through DE by the IFMT Cuiabá-Bela Vista Campus in order to verify conformities with the national official documents and to indicate any adjustments for conformance. It is a document analysis from a qualitative approach that took place during 2016 and 2017. It was verified that the current matrix, as proposed in 2012, complies with the hours required for the supervised internship for complementary activities and practice as a curricular component, however, it does not comply with the 3,200 hours required for a licentiate degree course. It was found that the above matrix includes important and compulsory themes, such as Sign Language, inclusive education, youngster and adult education and environmental education, but it does not include ethnic-racial issued, for example. One other aspect that was verified is the lack of discussions on the history, epistemology and/of philosophy of science, the STS approach and education technologies. Therefore, the curricular framework analyzed complies in part with the national curriculum guidelines and needs some adjustment regarding the total course hours that could be achieved through the insertion of subjects of both a specific type and pedagogical.
\end{abstract}

Keywords: Curriculum. Curriculum Guidelines. Teacher Training. Legislation. 


\section{Introdução}

Um dos problemas mais evidentes no ensino de química parece ser a inadequação da metodologia adotada pelos professores, por dificuldades em selecionar conteúdos específicos às estratégias de ensino que favoreçam o aprendizado (LOPES, KRÜGER, DEL PINO, SOUZA, 2007). Essas limitações, indicadas pelos pesquisadores, podem estar relacionadas à formação inicial recebida.

Desse modo, tem-se o entendimento de que os cursos de licenciatura necessitam superar a visão de uma formação conteudista, pois esse domínio mesmo importante - atualmente não é suficiente para o exercício da docência. Nesse sentido, reforça-se o pensamento de Lopes (2004) ao afirmar que a apresentação clara de ideias cientificamente corretas por parte de um professor não é a única condição para ocorrer aprendizagem. Em outras palavras, o domínio dos conteúdos de referência não é suficiente para desempenhar a profissão de professor, pois é preciso também saber "como" ensinar tais conceitos.

Nessa mesma linha de pensamento, Silva e Oliveira (2009) alertam sobre a necessidade de revisar e avaliar o processo de formação de professores, para que os cursos de licenciatura em química atendam a seu objetivo principal que é formar professores para atuarem na educação básica. Para os autores, espera-se que o curso garanta ao licenciado o conhecimento necessário sobre a química e sobre como ensiná-la. Entretanto, acontece que na maioria dos cursos, a formação específica acaba sendo privilegiada em detrimento da formação pedagógica, como se o conhecimento específico (químico) não necessitasse estar articulado com o pedagógico.

Por isso a importância de analisar o currículo de um curso, até porque as disciplinas que compõem uma matriz curricular são identificadas como saberes disciplinares (TARDIF, 2002). Esses saberes, que abrangem diversos campos do conhecimento, são oriundos da sociedade, hoje integrados nas instituições formadoras sob a forma de disciplinas no interior de faculdades e de cursos distintos. Eles emergem da tradição cultural e dos grupos sociais produtores de saberes. 
Nesse sentido, espera-se que o currículo educacional de um curso, em especial os de formação de professores, seja construído socialmente, de maneira a contemplar suas concepções e interpretações sobre os sujeitos que objetivam capacitar como profissionais. A esse respeito, Heidelmann, Pinho e Lima (2017) discutem que muitas matrizes curriculares dos cursos de formação de professores tendem a privilegiar o conhecimento técnico específico em relação ao pedagógico, devido aos elaboradores entenderem, equivocadamente, que a atuação profissional dos professores de química esteja ligada diretamente à resolução de problemas pela aplicação de teorias e técnicas.

Segundo Veiga (2004), ao elaborar um Projeto Pedagógico de Curso (PPC), no qual é definida a matriz curricular que direcionará o processo formativo, a Instituição de Ensino Superior (IES) precisa ir além de um simples agrupamento de conteúdos e atividades que pretende ofertar. A autora alerta que esse currículo precisa ser elaborado de maneira a ser vivenciado em todos os momentos formativos, conforme a intenção que a IES se propôs.

Os pesquisadores Zucco, Pessine e Andrade (1999), já alertavam que, desde o término do século passado, os currículos dos cursos de licenciatura em química estão transbordando de conteúdos informativos e não formativos, o que veio a ser confirmado pelo Parecer $n^{\circ} 1.303$ CNE/CE, de 06 de novembro de 2001 (BRASIL. Conselho Nacional de Educação, 2001). Ou seja, a maioria dos cursos está formando profissionais com conhecimentos desatualizados ou não suficientes para agir na sociedade com responsabilidade, seja como professor, seja como cidadão.

Para reverter essa situação, Veiga (2004) sugere, em seus estudos, que nos cursos de licenciatura organize-se a matriz curricular de forma integrada entre os conhecimentos de referência e os conceitos pedagógicos, de preferência de maneira interdisciplinar. Afirma ainda que, "as fronteiras entre os componentes curriculares são técnicas, uma vez que os conteúdos mantêm entre si uma relação aberta. Quando há integração, dissipa-se a hierarquia e estabelece-se uma prática comum de ensino" (VEIGA, 2004, p. 67).

Em outras palavras, um curso de licenciatura que vise a interdisciplinaridade como princípio formativo precisa pautar-se na flexibilização curricular e na postura dos direcionamentos previstos no PPC. Dessa forma, a formação inicial dos professores de 
química estará pautada na integração dos conhecimentos e não na hierarquização dos mesmos.

Nessa mesma linha de pensamento, Heidelmann, Pinho e Lima (2017, p. 262) afirmam que: "O projeto pedagógico deve ser compreendido em sua dimensão política, já que deve partir de uma reflexão do cotidiano, um compromisso definido coletivamente com a formação cidadã". O que os autores defendem é a necessidade de considerar as circunstâncias reais; que a formação precisa ser humanística e que possibilite lições para a vida, além de estabelecer relações entre teoria e realidade, entre a química e a vida, e assim manter a complementação da formação pedagógica com a específica.

Diante do exposto, este estudo teve o objetivo de analisar a estrutura curricular do Curso de Licenciatura em Química, ofertado pelo IFMT Campus Bela Vista na modalidade Educação a Distância (EaD), tendo como documentos de referência o PPC, a fim de verificar conformidades com a legislação educacional vigente, tais como as diretrizes oficiais, que regulamentam a formação inicial de professores no país.

Justifica-se a realização do estudo, pois, conforme afirmam Heidelmann, Pinho e Lima (2017), a estrutura curricular adotada por um curso é determinante na construção da identidade do professor e influencia diretamente no profissional formado pelo curso. Além disso, o processo formativo irá refletir nas escolas da educação básica, na atuação dos professores de química formados no curso. Por isso, é importante o estudo dessa estrutura curricular para entender as realidades formativas de futuros professores de química.

Para facilitar a leitura, este texto foi organizado em cinco seções. Na segunda seção são apresentados alguns aspectos da legislação vigente e das diretrizes oficiais sobre os cursos de licenciatura. A terceira seção mostra como foi realizada a análise documental do PPC desse curso eleito para investigação. Na quarta, os dados são apresentados e discutidos e, a quinta, compreende as considerações finais alcançadas com esse estudo. 


\section{O que preconizam os documentos oficiais sobre os cursos de licenciatura}

Em decorrência das mudanças propostas pela Lei $n^{\circ}$ 9.394, de 1996, que estabelece as Diretrizes e Bases da Educação Nacional (BRASIL, 1996), observa-se uma tendência com uma formação mais generalista, cujos currículos incluem temas que proporcionem a reflexão sobre ética, cidadania e responsabilidade social. Apregoa-se, inclusive, a abertura e a flexibilização das matrizes curriculares dos cursos de formação de professores para que essa demanda de formação humanística seja contemplada.

Nesse sentido, outro importante documento foi elaborado pelo Conselho Nacional de Educação, via Câmara de Educação Superior, no ano de 2001, por meio do Parecer $n^{\circ}$ 1.303, para estabelecer Diretrizes Curriculares Nacionais para os Cursos de Química no país (BRASIL. Conselho Nacional de Educação, 2001). Esse documento oficial propõe que as instituições formadoras necessitam repensar a organização curricular para se adequarem ao novo paradigma de sociedade, a fim de formar profissionais atuantes, questionadores e críticos, capazes de relacionar conhecimentos além dos de sua área de referência.

Conforme orienta o parecer supracitado,

O Licenciado em Química deve ter formação generalista, mas sólida e abrangente em conteúdos dos diversos campos da Química, preparação adequada à aplicação pedagógica do conhecimento e experiências de Química e de áreas afins na atuação profissional como educador na educação fundamental e média. (BRASIL Conselho Nacional de Educação, 2001, p. 4)

Essas diretrizes orientam sobre as habilidades pessoais e profissionais esperadas dos professores de química com relação à formação do licenciado em química, à compreensão da química, à busca de informação, à comunicação e expressão, ao ensino de química e à profissão. Com relação à estrutura geral, o documento orienta que os cursos procurem evitar a compartimentalização do conhecimento e busquem integrar o conhecimento químico e suas correlações com áreas afins, objetivando a interdisciplinaridade (BRASIL. Conselho Nacional de Educação, 2001). 
Quanto aos conteúdos curriculares, as diretrizes estabelecem como conteúdos básicos que conceitos da matemática, da física e da química são indispensáveis. Como conteúdos específicos, o documento estabelece que são conteúdos profissionais, essenciais ao desenvolvimento de competências e habilidades inerentes ao professor de química. Como conteúdos complementares, aqueles essenciais para a formação humanística. Além disso, as diretrizes orientam sobre o que são as atividades complementares e sobre a realização do estágio supervisionado (BRASIL. Conselho Nacional de Educação, 2001).

Segundo a Lei de Diretrizes e Bases da Educação (LDB), no seu Art. 61: Os estágios supervisionados constam de atividades de prática pré-profissional, exercidas em situações reais de trabalho, nos termos da legislação em vigor (BRASIL, 1996). De acordo com as definições contidas na Lei $n^{\circ} 11.788$, de 25 de setembro de 2008 , que dispõe sobre o estágio de estudantes, afirma que o estágio supervisionado, previsto como itinerário educativo no Projeto Pedagógico do Curso (PPC), é um ato que visa o aprendizado de competências próprias da atividade profissional para qual o estudante está se preparando (BRASIL, 2008a).

No Art. $9^{\circ}$ do Decreto Federal $n^{\circ}$ 5.626, de 22 de dezembro de 2005, fica estabelecida a inclusão de Libras como disciplina curricular obrigatória, inicialmente nos cursos de Educação Especial, Fonoaudiologia, Pedagogia e Letras, com ampliação progressiva aos demais cursos de licenciatura no país (BRASIL, 2005).

Segundo a Resolução $\mathrm{n}^{\circ}$ 02/2012, um dos objetivos das Diretrizes Curriculares Nacionais para a Educação Ambiental é orientar os cursos de formação de docentes para a Educação Básica (BRASIL. Conselho Nacional de Educação, 2012a). Assim, compete aos cursos de licenciatura capacitar os profissionais da educação para desenvolverem práticas de ensino que integrem a educação ambiental com sua área de conhecimento para favorecer a compreensão dos estudantes quanto às relações entre meio ambiente e as práticas sociais, no intuito de fomentar novos hábitos referentes à produção e ao consumo.

$\mathrm{Na}$ busca por consolidar normas nacionais para a formação de professores para a educação básica, foi homologada, em 01 de julho de 2015, a Resolução $n^{\circ} 2$ que define as Diretrizes Curriculares Nacionais para a formação inicial em nível superior (cursos de 
licenciatura, cursos de formação pedagógica para graduados e cursos de segunda licenciatura) e para a formação continuada (BRASIL. Conselho Nacional de Educação, 2015).

Para sua elaboração, essa resolução observou os preceitos dos artigos 61 até 67 e do artigo 87 da Lei $n^{\circ}$ 9.394, de 1996, que dispõem sobre a formação de profissionais do magistério; o Decreto ${ }^{\circ}$ 6.755, de 29 de janeiro de 2009, as Resoluções $n^{\circ} 1$ CNE/CP, de 18 de fevereiro de 2002, CNE/CP n ${ }^{\circ}$ 2, de 19 de fevereiro de 2002, CNE/CP nº 1, de 15 de maio de 2006, CNE/CP $n^{\circ}$ 1, de 11 de fevereiro de 2009, CNE/CP $n^{\circ} 3$, de 15 de junho de 2012, as Resoluções $n^{\circ} 2$ CNE/CEB, de 19 de abril de 1999, e CNE/CEB $n^{\circ} 2$, de 25 de fevereiro de 2009, as Diretrizes Curriculares Nacionais da Educação Básica, bem como o Parecer $n^{\circ} 2$ CNE/CP, de 9 de junho de 2015.

No Art. $13, \S 1^{\circ}$, da referida resolução fica estabelecida a obrigatoriedade de 3.200 (três mil e duzentas) horas de efetivo trabalho acadêmico para a formação inicial superior de professores. O mesmo inciso determina que os cursos tenham, no mínimo, a duração de 8 (oito) semestres ou 4 (quatro) anos. Nesse mesmo artigo, porém no $\S 2^{\circ}$, é garantida, nos cursos de licenciatura, formação específica para valorizar a diversidade, contribuindo para o respeito das diferenças étnico-raciais, de gênero, de faixas geracionais, de classes sociais, religiosas, de necessidades especiais, de diversidade sexual, entre outras (BRASIL. Conselho Nacional de Educação, 2015).

Essas foram apenas algumas das informações contidas nos documentos oficiais nacionais que regulamentam o funcionamento dos cursos de licenciatura no país. Cabe aqui apontar que ao longo da análise do PPC do curso investigado, outras informações serão apresentadas, até mesmo porque esse assunto não se esgota aqui.

\section{Procedimentos metodológicos}

O presente estudo configura-se como uma análise documental descritiva, de abordagem qualitativa, que foi realizada ao longo dos anos de 2016 e 2017. O objeto de estudo é a estrutura curricular do Curso de Licenciatura em Química, ofertado na modalidade EaD, pelo IFMT Campus Cuiabá-Bela Vista. Para investigar esse objeto se fez 
necessário utilizar o método da análise documental. Esse tipo de pesquisa envolve várias formas de registro como fonte primária de informação (GIL, 2010).

Essa análise documental é um recorte da pesquisa de doutoramento desenvolvida no Programa de Pós-Graduação Stricto Sensu em Educação em Ciências: Química da Vida e Saúde, promovido pela Universidade Federal do Rio Grande do Sul (UFRGS) - Campus Saúde em Porto Alegre-RS.

Segundo Roehrs (2013), a análise de discursos identificados a partir dos documentos possibilita o acesso a uma realidade sob outra perspectiva, contribuindo para a validação mediante a triangulação de estratégias de coleta de dados. Além de expressar a realidade de um contexto e fatos, é preciso perceber que são construções humanas, com uma finalidade prática, visando a um certo uso e acesso.

Segundo Gil (2010), são sugeridos alguns procedimentos para o processo de análise e interpretação de informações decorrentes da pesquisa documental. Os nove passos sugeridos pelo podem ser resumidos em: escolha e organização das fontes de informações; estudo detalhado com descrição analítica; tratamento e interpretação.

Inicialmente, foi realizado um levantamento bibliográfico acerca da legislação educacional vigente e das diretrizes oficiais que orientam a construção dos cursos de Licenciatura em Química em âmbitos nacionais, como, por exemplo, a Resolução $\mathrm{n}^{\circ}$ 2, de $1^{\circ}$ de julho de 2015 (BRASIL. Conselho Nacional de Educação, 2015), que define as Diretrizes Curriculares Nacionais para a Formação de Professores da Educação Básica no Brasil.

Os documentos utilizados para realizar essa análise foram o Projeto Pedagógico desse Curso de Licenciatura em Química, leis federais e diretrizes oficiais. A obtenção dos referidos documentos ocorreu por meio das páginas web da Instituição de Ensino Superior (IES), que oferta o curso investigado, e do Ministério de Educação e Cultura (MEC), mais especificamente do Conselho Nacional de Educação, cujo acesso para consultas é livre.

Cabe informar que foi assinada a anuência dos responsáveis pelo curso (coordenador da UAB/IFMT, diretor do IFMT Campus Cuiabá-Bela Vista e coordenador do 
respectivo curso), permitindo a realização da pesquisa e disponibilizando acesso aos documentos que fossem necessários.

A interpretação dos resultados ocorreu de forma a relacionar as informações contidas no PPC do curso com os autores que discutem sobre a estrutura curricular de cursos de Licenciatura em Química e com os documentos oficiais nacionais.

\section{Resultados e discussões}

A estrutura curricular vigente no curso investigado pode ser visualizada no Quadro 1. Essa é a segunda configuração curricular do curso, que foi aprovada, por meio de PPC, no ano de 2012. Uma terceira matriz curricular encontra-se em fase de elaboração.

Quadro 1: Matriz do Curso de Licenciatura em Química UAB/IFMT

\begin{tabular}{|l|c|c|c|c|c|}
\cline { 5 - 6 } \multicolumn{2}{c}{ Componente Curricular } & \multicolumn{3}{c}{ Carga Horária } \\
\hline Introdução à Educação a Distância & Sem & NCC & PCC & ES & AC \\
\hline Química Geral I & $1^{\circ}$ & 60 & & & \\
\hline Metodologia Científica & $1^{\circ}$ & 100 & & & \\
\hline Fundamentos Sócio-Antropológicos da Educação & $1^{\circ}$ & & 60 & & \\
\hline Fundamentos da Matemática & $1^{\circ}$ & 60 & & & \\
\hline Língua Portuguesa & $1^{\circ}$ & 60 & & & \\
\hline Filosofia da Educação & $1^{\circ}$ & 60 & & & \\
\hline Cálculo Diferencial e Integral I & $1^{\circ}$ & 60 & & & \\
\hline Álgebra Linear e Geometria Analítica & $2^{\circ}$ & 60 & & & \\
\hline Química Geral II & $2^{\circ}$ & 60 & & & \\
\hline Química e Educação Ambiental & $2^{\circ}$ & 80 & & & \\
\hline Biologia Geral & $2^{\circ}$ & 80 & & & \\
\hline Psicologia da Educação & $2^{\circ}$ & 80 & & & \\
\hline Química Orgânica I & $2^{\circ}$ & 60 & & & \\
\hline Fundamentos da Estatística aplicada à Química & $2^{\circ}$ & 80 & & & \\
\hline Cálculo Diferencial e Integral II & $3^{\circ}$ & 40 & & & \\
\hline Química Orgânica II & $3^{\circ}$ & 60 & & & \\
\hline Legislação e Diretrizes Educacionais & $3^{\circ}$ & 60 & & & \\
\hline Física Fundamental I & $3^{\circ}$ & 60 & & & \\
\hline Fundamentos da Bioquímica & $3^{\circ}$ & 60 & & & \\
\hline Didática Geral & $3^{\circ}$ & 60 & & & \\
\hline Atividades complementares & $3^{\circ}$ & & 80 & & \\
\hline Físico-Química I & $3^{\circ}$ & & & & 60 \\
\hline Física Fundamental II & $4^{\circ}$ & 80 & & & \\
\hline Química Inorgânica I & $4^{\circ}$ & 80 & & & \\
\hline Planejamento e Avaliação da aprendizagem & $4^{\circ}$ & 80 & & & \\
\hline & $4^{\circ}$ & & 60 & & \\
\hline
\end{tabular}




\begin{tabular}{|l|c|c|c|c|c|}
\hline Metodologia para o Ensino de Química & $4^{\circ}$ & & 60 & & \\
\hline Estágio Supervisionado I & $4^{\circ}$ & & & 100 & \\
\hline Atividades complementares & $4^{\circ}$ & & & & 60 \\
\hline Físico-Química II & $5^{\circ}$ & 80 & & & \\
\hline Educação Inclusiva & $5^{\circ}$ & & 60 & & \\
\hline Química Inorgânica II & $5^{\circ}$ & 60 & & & \\
\hline Disciplina Optativa* & $5^{\circ}$ & 60 & & & \\
\hline Estágio Supervisionado II & $5^{\circ}$ & & & 140 & \\
\hline Química Analítica Qualitativa & $5^{\circ}$ & 80 & & & \\
\hline Atividades complementares & $5^{\circ}$ & & & & 40 \\
\hline Química Analítica Quantitativa & $6^{\circ}$ & 80 & & & \\
\hline Análise Instrumental & $6^{\circ}$ & 60 & & & \\
\hline Química Moderna & $6^{\circ}$ & 40 & & & \\
\hline $\begin{array}{l}\text { Fundamentos da Linguagem Brasileira de Sinais } \\
\text { (LIBRAS) }\end{array} 6^{\circ}$ & & 60 & & \\
\hline Estágio Supervisionado III & & & & & \\
\hline Educação de Jovens e Adultos & $6^{\circ}$ & & & 160 & \\
\hline Atividades complementares & $6^{\circ}$ & & 60 & & \\
\hline & & $\mathbf{1 . 9 4 0}$ & $\mathbf{4 4 0}$ & $\mathbf{4 0}$ & $\mathbf{2 0 0}$ \\
\hline
\end{tabular}

NCC: Natureza científico-cultural; PCC: Prática como componente curricular; ES: Estágio supervisionado; AC: Atividades acadêmico-científico-culturais.

*Química dos Metais de Transição ou Química Aplicada à Área de Alimentos, ou Radioatividade ou Inglês Técnico e Científico.

Fonte: Elaboração própria baseado no Projeto Pedagógico do Curso (2012).

Conforme pode ser observado no Quadro 1, esse curso foi organizado de forma a constituir-se de 1.940 (mil novecentas e quarenta) horas de conteúdos curriculares de natureza científico-cultural, 440 (quatrocentas e quarenta) horas de prática como componente curricular; 200 (duzentas) horas de atividades acadêmico-científico-culturais e 400 (quatrocentas) horas de estágio curricular supervisionado, cujo desenvolvimento se dá a partir do quarto semestre.

Percebe-se que a carga horária total desse curso é de 2.980 (duas mil novecentas e oitenta) horas distribuídos em 6 (seis) semestres com duração de 3 (três) anos, o que estava em conformidade com a legislação para funcionamento de licenciaturas na época em que era o mínimo de 2.400 (duas mil e quatrocentas) horas conforme a Resolução $\mathrm{n}^{\circ} 2$ CNE/CES (BRASIL Conselho Nacional de Educação,2007). Todavia, o curso necessita de adequação da carga horária imediatamente para atender as 3.200 (três mil e duzentas) horas e duração de 8 (oito) semestres ou 4 (quatro) anos, conforme estabelecidas pela Resolução nº 2 (BRASIL. Conselho Nacional de Educação, 2015). 
A resolução supracitada também estabelece, em seu Art. 22, que os cursos de formação de professores que já se encontram em funcionamento deverão se adaptar às prerrogativas desta Resolução no prazo de dois anos, a partir da data de sua publicação. Ou seja, já está findado o prazo de adequação e o curso ainda não tem um novo PPC aprovado.

Sobre a realização do estágio supervisionado, constata-se que totaliza 400 (quatrocentas) horas, dividido em três etapas: Estágio Supervisionado I, Estágio Supervisionado II e Estágio Supervisionado III (IFMT, 2012). Na primeira etapa, o intuito é a inserção do acadêmico no cotidiano escolar, que realiza observações sobre a estrutura e funcionamento da escola e da prática pedagógica de professores já formados.

A segunda etapa é destinada ao planejamento de aulas de Ciências para o $9^{\circ}$ ano do Ensino Fundamental e para preparação de materiais didático-pedagógicos, além de desenvolver um projeto de intervenção pedagógica. Na terceira etapa, ocorre a regência na disciplina de Química no Ensino Médio que visa o aprendizado de competências próprias da atividade profissional para a qual o estudante está se preparando. A maneira com que o estágio supervisionado foi proposto pelo curso está em conformidade com a Lei $n^{\circ} 11.788$ (BRASIL, 2008a).

Conforme a Resolução n² 2, de $1^{\circ}$ de julho de 2015 (BRASIL. Conselho Nacional de Educação, 2015), que define as Diretrizes Curriculares Nacionais para a formação inicial em nível superior, fica estipulado em seu Art. $13^{\circ}$, que a carga horária mínima para a realização do estágio supervisionado é de 400 (quatrocentas) horas e que essas sejam dedicadas à área específica de formação para atuação na educação básica, contemplando em casos esporádicos em áreas afins, desde que previsto e autorizado no projeto de curso da instituição.

Conforme determinado no PPC (IFMT, 2012), as atividades acadêmico-científicoculturais constam de 200 (duzentas) horas. Essas atividades complementares estão em conformidade com os parâmetros definidos no Art. 13, IV da Resolução no 2 (BRASIL, 2015) que estabelece o mínimo de 200 (duzentas) horas de atividades teórico-práticas de aprofundamento. Essas atividades ocorrem de acordo com o interesse dos estudantes, por meio da iniciação científica, da iniciação à docência, da extensão e da monitoria, entre outras, consoante o projeto de curso da instituição. 
Referente ao desenvolvimento de prática como componente curricular, o curso prevê um total de 440 (quatrocentas e quarenta) horas. Os componentes curriculares que envolvem a prática educativa estão concentrados na segunda metade do curso, sendo que no $2^{\circ}$ semestre não contemplam nem uma disciplina sequer. São essas as disciplinas consideradas como práticas como componente curricular: Metodologia Científica $\left(1^{\circ}\right)$, Didática Geral $\left(3^{\circ}\right)$, Metodologia para o Ensino de Química $\left(4^{\circ}\right)$, Planejamento e Avaliação da aprendizagem ( $\left.4^{\circ}\right)$, Educação Inclusiva $\left(5^{\circ}\right)$, Fundamentos da Linguagem Brasileira de Sinais ( $\left.6^{\circ}\right)$ e Educação de Jovens e Adultos $\left(6^{\circ}\right)$.

No Art. 13, I da Resolução nº 2 (BRASIL. Conselho Nacional de Educação, 2015) ficam estabelecidas 400 (quatrocentas) horas mínimas de prática como componente curricular e que sejam distribuídas ao longo do processo formativo. Nesse curso investigado, é cumprida e até excedida a carga horária mínima exigida para prática como componente curricular, porém não é seguida a orientação de ser distribuída ao longo do curso, ficando concentrada nos últimos semestres. Contudo, Heidelmann, Pinto e Lima (2017, p. 263) ressaltam que essa "prática" precisa ser compreendida como as atividades realizadas pelos acadêmicos "no âmbito de ensino e que devem ocorrer do início da formação docente até o final do processo".

Observa-se que nesse curso existe um predomínio dos componentes curriculares de natureza científico-cultural - 1.940 (mil novecentas e quarenta) horas de conteúdos básicos (matemática, química e física) e conteúdos específicos essenciais para o desenvolvimento de competências e habilidades da profissão (BRASIL. Conselho Nacional de Educação, 2001).

Há de se convir essa necessidade para que os profissionais formados pelo curso tenham embasamento teórico e prático em sua área de referência. Contudo, Silva e Oliveira (2009) alertam que a maioria das instituições formadoras adota um grande enfoque na racionalidade técnica, esquecendo que estão formando professores de química. É como se não fosse competência dos professores formadores dessas disciplinas articular os conhecimentos específicos à maneira de ensiná-los.

O componente curricular Legislação e Diretrizes Educacionais ( $3^{\circ}$ semestre) aborda a estrutura e o funcionamento da educação básica, as leis educacionais e diretrizes que norteiam o sistema educacional brasileiro. Contudo, não se verificou na atual estrutura 
curricular como um todo, momentos que possibilitem refletir sobre a educação de formação integral, sobre o retrospecto histórico do sistema educacional brasileiro, bem como sobre mudanças de paradigmas que resultaram na educação contemporânea. Além disso, Heidelmann, Pinho e Lima (2017) verificaram em seus estudos a escassez de discussões sobre a função social do ensino de química ao longo da formação inicial e continuada de professores.

Observa-se também que a matriz curricular contempla Filosofia da Educação ( $1^{\circ}$ semestre), porém não contempla durante toda formação inicial discussões sobre História, Epistemologia e/ou Filosofia da Ciência, tampouco o campo da educação Ciência, Tecnologia e Sociedade (CTS). Em seus estudos, Bachelard (1996) defende que a concepção de ciência que o professor assume é determinante na sua maneira de agir. Ou seja, é fundamental que um curso de formação de professores de química aborde discussões que levem os estudantes a formularem concepções sobre a ciência, pois isso favorecerá que os futuros professores compreendam os processos de ensinar e aprender ciência.

As sugestões de ajustes supracitadas visam um perfil curricular que continue científico, porém mais humanístico, no sentido de tornar esse processo formativo um espaço em que haja construção de conhecimentos relacionados ao seu contexto histórico, em atendimento ao que estabelece o Parecer $n^{\circ} 1.303$ (BRASIL. Conselho Nacional de Educação, 2001). Dessa maneira, será considerado “como" e "com que intenção" ocorreram as produções científicas e, assim, será superado o paradigma positivista no qual o conhecimento da ou na ciência é tido como absoluto e dogmático.

Contemplar as disciplinas de Educação Inclusiva ( $5^{\circ}$ semestre), de Educação de Jovens e Adultos (EJA) e Libras ( $6^{\circ}$ semestre), está em conformidade e atende em parte o estabelecido pela Resolução $n^{\circ} 2$ (BRASIL. Conselho Nacional de Educação, 2015). Observa-se também que a inserção da disciplina de Fundamentos da Linguagem Brasileira de Sinais (Libras) atende o que foi estabelecido pelo Decreto $n^{\circ} 5.626$ (BRASIL, 2005). Apresentar a disciplina de Química e Educação Ambiental ( $2^{\circ}$ semestre) no currículo atende as orientações formativas preconizadas na Resolução $n^{\circ} 02$ (BRASIL. Conselho Nacional de Educação, 2012a). 
Ter uma disciplina sobre a modalidade EJA ( $6^{\circ}$ semestre) é muito oportuno nesse processo formativo que prepara profissionais para atuarem num contexto real. Porém, é preciso considerar que a educação para a diversidade é bem mais ampla. Cabe aqui lembrar outras três especificidades da educação encontradas no estado de Mato Grosso, que são: Educação do Campo, Educação Escolar Indígena e Educação Escolar Quilombola, amparadas respectivamente pelas Resoluções $\mathrm{n}^{\circ} 1$, de 3 de abril de 2002 (BRASIL. Conselho Nacional de Educação, 2002), n 5, de 22 de junho de 2012 (BRASIL. Conselho Nacional de Educação, 2012b) e $n^{\circ} 08$ de 20 de novembro de 2012 (BRASIL. Conselho Nacional de Educação, 2012c).

Da mesma maneira, nota-se que não são contempladas nesse curso as discussões sobre o respeito às diferenças étnico-raciais que são indicadas nas Leis n 10.639, (BRASIL, 2003), e n 11.645 (BRASIL, 2008b), que tratam sobre a obrigatoriedade de formação para ensinar nos estabelecimentos de Ensino Fundamental e Médio, públicos e privados, o estudo da história e cultura afro-brasileira e indígena. Uma importante característica a ser considerara, conforme defendido por Veiga (2004) e por Silva e Oliveira (2009), é o fato de que os cursos de licenciatura formam os professores para atuarem na educação básica.

Outra sugestão para ajuste na estrutura curricular desse curso é referente a formação para o uso das tecnologias educacionais. A inserção de tecnologias da informação e comunicação nas práticas educativas é uma necessidade no contexto atual. Contudo, o professor só se sentirá seguro para utilizar os meios tecnológicos em suas aulas se foi preparado. Além disso, o próprio curso se utiliza de ferramentas tecnológicas para esse ensino em EaD.

Essa constatação vem corroborar as verificações de Zucco, Pessine e Andrade (1999), de que há tempos os currículos dos cursos de licenciatura em química abordam conhecimentos desatualizados e, ainda, o que alertou Silva e Oliveira (2009, p. 45), que ocorre na maioria desses cursos, a "ausência de conteúdos relativos às tecnologias da informação e das comunicações."

Outra carência observada na estrutura curricular vigente é a ausência da oferta de disciplinas optativas na área de ensino de química. As quatro opções de disciplinas optativas são de conhecimento específico, ou seja, não foram observadas as orientações 
das diretrizes para cursos de química quanto a correlacionar no currículo os conteúdos específicos da química com os gerais, objetivando a interdisciplinaridade (BRASIL, 2001). Veiga (2004) também defende a necessidade de vencer as fronteiras técnicas entre as disciplinas, até mesmo porque os conteúdos não são isolados, mas mantêm uma relação aberta entre si.

Além disso, observou-se que o curso não prevê o desenvolvimento de Trabalho de Conclusão de Curso (TCC) em sua estrutura curricular, o que desfavorece o incentivo à pesquisa, elemento indispensável ao professor contemporâneo. No entanto, na matriz curricular atual há a oferta da disciplina de metodologia científica. Essas duas carências (disciplinas optativas voltadas ao ensino e TCC), também foram verificadas no estudo realizado por Silva e Oliveira (2009).

Mudanças e ajustes na estrutura curricular de um curso de licenciatura sempre serão necessários, porém não se pode pensar em integração curricular apenas como resultado de inserção de disciplinas que simplesmente atendam as diretrizes oficiais, mas sim que as mesmas estejam interligadas na formação de um professor de química criativo, questionador e socialmente comprometido, que não seja um mero armazenador de informações e sim um profissional que saiba buscá-las rapidamente para construir os saberes necessários para cada situação.

\section{Considerações finais}

Ao analisar a estrutura curricular do Curso de Licenciatura em Química, ofertado na modalidade EaD pelo IFMT Campus Cuiabá-Bela Vista, tendo suporte nos documentos oficiais, foi possível constatar conformidades e lacunas a serem ajustadas para que essa formação inicial de professores capacite e prepare profissionais autônomos como se espera na educação contemporânea.

As conformidades estão relacionadas à carga horária de estágio supervisionado, atividades complementares e práticas como componentes curriculares. A atual matriz curricular contempla importantes e obrigatórias temáticas, tais como Libras, educação inclusiva, educação de jovens e adultos e educação ambiental. Porém, apresenta lacunas 
relacionadas à diversidade étnico-racial; história, epistemologia e/ou filosofia da ciência, CTS e tecnologias educacionais.

Considera-se importante proporcionar, em um curso de licenciatura em química, o desenvolvimento das habilidades fundamentais para o professor relacionar conteúdos de referência (conceitos químicos), estratégias de ensino e realidade (cotidiano) para, assim, favorecer a aprendizagem. Dessa maneira, desenvolvem-se as ferramentas pedagógicas apropriadas para estabelecer as conexões entre a química e a vida, o que leva os estudantes a relacionarem os conteúdos estudados com os outros campos do conhecimento.

Ao término deste estudo, é possível considerar que a estrutura curricular analisada atende em partes a legislação vigente e as diretrizes oficiais que o curso contempla temáticas indispensáveis para a formação de professores, porém necessita de uma adequação quanto à carga horária, que pode ser realizada pela inserção de disciplinas tanto de natureza específica quanto pedagógica.

Partindo do pressuposto de que os cursos de licenciatura necessitam superar a visão de uma formação conteudista, destaca-se a necessária revisão e avaliação do projeto pedagógico do curso, tendo em vista o objetivo principal dos cursos de licenciatura em química que é o de formar professores para atuarem na educação básica. Essa adequação curricular, fundamentada em bases científicas e humanísticas do saber docente, independe da modalidade, uma vez que todos os cursos de licenciatura, sejam eles presenciais ou a distância, buscam atender às demandas formativas. Logo, espera-se que a formação inicial de professores de química seja cada vez mais investigada, debatida e conhecida, para que esse processo possa preparar profissionais capacitados para ensinar química. 


\section{Referências}

BACHELARD, Gaston. O Novo espírito científico. Rio de Janeiro: Tempo Brasileiro, 1996.

BRASIL. Conselho Nacional de Educação. Parecer $N^{\circ} 1.303$ CNE/CE, de 06 de novembro de 2001. Diretrizes Curriculares para Cursos de Química, Bacharelado e Licenciatura Plena. Brasília: MEC, [2001]. Disponível em: <http://portal.mec.gov.br/cne/arquivos/pdf/CES1303.pdf >. Acesso em: 23 ago. 2016.

BRASIL. Conselho Nacional de Educação. Resolução № 1 CNE/CEB, de 3 de abril de 2002. Brasília: MEC, [2002]. Institui Diretrizes Operacionais para a Educação Básica nas Escolas do Campo. Disponível em: <http://portal.mec.gov.br/cne/arquivos/pdf/CEB012002.pdf>. Acesso em: 11 out. 2016.

BRASIL. Conselho Nacional de Educação. Resolução Nº 2 CNE/CES, de 18 de junho de 2007. Dispõe sobre carga horária mínima e procedimentos relativos à integralização e duração dos cursos de graduação, bacharelados, na modalidade presencial. Brasília: MEC, [2007]. Disponível em: <http://portal.mec.gov.br/cne/arquivos/pdf/2007/rces002_07.pdf>. Acesso em: 11 out. 2016.

BRASIL. Conselho Nacional de Educação. Resolução No 2 CNE/CP, de 15 de junho de 2012. Estabelece as Diretrizes Curriculares Nacionais para a Educação Ambiental. Diário Oficial da União, Brasília, n. 116, seção 1, p. 70, 18 jun. 2012 Brasília: MEC, [2012a].. Disponível em: <http://conferenciainfanto.mec.gov.br/images/pdf/diretrizes.pdf>. Acesso em: 23 ago. 2016.

BRASIL. Conselho Nacional de Educação. Resolução No ${ }_{5}$ CNE/CEB, de 22 de junho de 2012. Define Diretrizes Curriculares Nacionais para a Educação Escolar Indígena na Educação Básica. Brasília, 2012. Brasília: MEC, [2012b]. Disponível em: <http://www.educadores.diaadia.pr.gov.br/arquivos/File/pdf/resolucaoeduc_campo.pdf>. Acesso em: 23 ago. 2016.

BRASIL Conselho Nacional de Educação. Resolução N $^{\circ} 8$ CNE/CEB, de 20 de novembro de 2012. Define Diretrizes Curriculares Nacionais para a Educação Escolar Quilombola na Educação Básica Brasília, 2012. Brasília: MEC, [2012c]. Disponível em: <http://www.crmariocovas.sp.gov.br/Downloads/ccs/concurso_2013/PDFs/resol_federal_ 8_12.pdf>. Acesso em: 23 ago. 2016.

BRASIL. Conselho Nacional de Educação. Resolução $\mathbf{N}^{\circ} 2$ CNE/CP, de $1^{\circ}$ de julho de 2015. Define as Diretrizes Curriculares Nacionais para a formação inicial em nível superior (cursos de licenciatura, cursos de formação pedagógica para graduados e cursos de segunda licenciatura) e para a formação continuada. Brasília: MEC, [2015]. Disponível em: <http://pronacampo.mec.gov.br/images/pdf/res_cne_cp_02_03072015.pdf>. Acesso em: 11 out. 2016.

BRASIL. Decreto Federal $\mathbf{N}^{\circ} \mathbf{5 . 6 2 6}$, de 22 de dezembro de 2005. Regulamenta a Lei no 10.436, de 24 de abril de 2002, que dispõe sobre a Língua Brasileira de Sinais - Libras. 
Brasília, DF: Presidência da República, 2005. Disponível em: <http://www.planalto.gov.br/ccivil_03/_at02004-2006/2005/decreto/d5626.htm>. Acesso em: 11 out. 2016.

BRASIL. Lei № 9.394, de 20 de dezembro de 1996. Estabelece as diretrizes e bases da educação nacional. Brasília, 20 dez. 1996. Disponível em:

<http://www.planalto.gov.br/ccivil_03/leis/L9394.htm>. Acesso em: 15 set. 2016.

BRASIL. Lei N 10.639, de 09 de janeiro de 2003. Diário Oficial da União. Brasília, DF, 10 de janeiro de 2003. Disponível em:

<http://www.planalto.gov.br/ccivil_03/leis/2003/L10.639.htm>. Acesso em: 15 set. 2016.

BRASIL. Lei $\mathrm{N}^{\circ} 11.788$, de 25 de setembro de 2008. Dispõe sobre o estágio de estudantes. Diário Oficial da União, Brasília, DF, 26 de setembro de 2008a. Disponível em: <http://www.planalto.gov.br/ccivil_03/_ato2007-2010/2008/lei/l11788.htm>. Acesso em: 08 out. 2016.

BRASIL. Lei Nº 11.645, de 10 de março de 2008. Diário Oficial da União, Brasília, DF, 11 de março de 2008b. Disponível em: <http://www.planalto.gov.br/ccivil_03/_ato20072010/2008/lei/l11645.htm>. Acesso em: 11 out. 2016.

GIL, Antônio Carlos. Como elaborar projeto de pesquisa. 5. ed. São Paulo: Atlas, 2010.

HEIDELMANN, Stephany Petronilho; LIMA, Maria Celiana Pinheiro; PINHO, Gabriela Salomão Alves. Caminhos e descaminhos da formação docente: Uma análise dos Projetos Pedagógicos de Cursos de Licenciatura em Química no Rio de Janeiro. Química Nova na Escola (online), v. 39, n. 3, p. 261-267, 2017. Disponível em:

<http://qnesc.sbq.org.br/online/qnesc39_3/07-EA-06-16.pdf>. Acesso em: 16 nov. 2016.

IFMT. Projeto pedagógico de curso de licenciatura em química. Cuiabá: Instituto Federal de Mato Grosso, 2012.

LOPES, Joaquim Bernardino. Aprender e ensinar física. Braga: Fundação Calouste Gulberskian; Fundação para a Ciência e a Tecnologia, 2004.

LOPES, Cesar Valmor Machado; KRÜGER, Verno; DEL PINO, José Claudio; SOUZA, Diogo Onofre Gomes de. Concepções de professores de química sobre a natureza do conhecimento científico. Acta Scientiae (ULBRA), v. 9, p. 3-16, 2007. Disponível em: <http://www.periodicos.ulbra.br/index.php/acta/article/view/92>. Acesso em: 16 nov. 2016.

ROEHRS, Marfa Magali. Licenciatura em ciências biológicas: uma análise dos saberes de referência e pedagógicos na formação de professores para os anos finais do Ensino Fundamental. 2013. Dissertação (Mestrado em Educação) - Universidade Federal de Mato Grosso, Programa de Pós-Graduação em Educação Cuiabá, 2013.

SILVA, Camila Silveira da; OLIVEIRA, Luiz Antonio Andrade de. Formação inicial de professores de química: formação específica e pedagógica. In: Roberto Nardi. (Org.). 
Ensino de ciências e matemática I: temas sobre a formação de professores. 1. ed. São Paulo: Cultura Acadêmica, 2009, v. 1, p. 43-57.

TARDIF, Maurice. Saberes docentes e formação profissional. Petrópolis: Vozes, 2002. VEIGA, Ilma Passos Alencastro. Educação básica e educação superior: projeto político pedagógico. Campinas: Papirus, 2004.

ZUCCO, César; PESSINE, Francisco Benedito Teixeira; ANDRADE, Jailson Bittencourt de. Diretrizes curriculares para os cursos de química. Química Nova, Brasil, v. 22, n.3, p. 454$461,1999$.

Recebido em: 06/10/2017 Revisões requeridas: 21/11/2017 Aprovado em: 24/11/2017

Universidade do Estado de Santa Catarina - UDESC Programa de Pós-Graduação em Educação - PPGE Revista Linhas Volume 20 - Número 42 - Ano 2019 revistalinhas@gmail.com 